\title{
Infecção por Hepatozoon canis em canino doméstico na região Sul do Brasil confirmada por técnicas moleculares
}

\author{
Hepatozoon canis infection in a domestic dog in Southern Brazil confirmed by molecular techniques
}

\author{
Camila Serina Lasta ${ }^{\text {I }}$ Andrea Pires dos Santos ${ }^{\text {II }}$ Fabíola Peixoto da Silva Mello ${ }^{\text {III }}$ \\ Luciana de Almeida Lacerda ${ }^{I I}$ Joanne Belle Messick ${ }^{\text {IV }}$ Félix Hilário Díaz González $^{\mathrm{V}}$
}

RESUMO

Hepatozoonose canina é uma doença transmitida por carrapatos e causada pelo protozoário Hepatozoon spp. No Brasil, existem poucos relatos da infecção e dados sobre sua epidemiologia, patogenicidade, seus vetores e sua caracterização genética. No presente estudo, são utilizadas técnicas moleculares para o diagnóstico e a caracterização do parasita. Foi estudado um canino que apresentava emagrecimento progressivo, anemia regenerativa, neutropenia e hiperglobulinemia. Gamontes de Hepatozoon spp. foram visualizados no esfregaço sanguíneo. DNA foi extraído do sangue, e o diagnóstico foi confirmado pela técnica da reação em cadeia da polimerase (PCR). O produto da PCR foi purificado a partir do gel e clonado, e o fragmento de $625 \mathrm{pb}$ foi sequenciado. A sequência foi submetida ao GenBank como isolado de Porto Alegre, e a análise molecular revelou homologia de 98-100\% com Hepatozoon canis e máxima de 92\% com Hepatozoon americanum. Este estudo representa a primeira confirmação molecular da presença de $\boldsymbol{H}$. canis no sul do Brasil.

Palavras-chave: Hepatozoon canis, hemoparasita, cão, PCR, Brasil.

\section{ABSTRACT}

Canine hepatozoonosis is a vector-borne disease caused by the protozoa Hepatozoon spp. There are few case reports in Brazil and the epidemiology, pathogenicity, vectors and molecular characterization is poorly understood. The present study used a canine presenting weight loss, regenerative anemia, neutropenia and hyperglobulinemia. Hepatozoon spp. gamonts were observed in the blood smear by microscopy. DNA was extracted from blood, and the diagnosis was confirmed by PCR assay. The PCR product was purified from gel and cloned. A fragment of $625 \mathrm{bp}$ was sequenced and submitted to the GenBank database as Isolate Porto Alegre. Molecular analysis showed a homology of 98-100\% with Hepatozoon canis and less than $92 \%$ for H. americanum. This study represents the first molecular confirmation that $\boldsymbol{H}$. canis is present in Southern Brazil.

Key words: Hepatozoon canis, hemoparasite, dog, PCR, Brazil.

\section{INTRODUÇÃO}

A hepatozoonose é uma doença causada pelo protozoário Hepatozoon spp., transmitida por artrópodes, que acomete principalmente os carnívoros domésticos e silvestres (BANETH et al., 2003; RUBINI et al., 2005). Até o momento, duas espécies de Hepatozoon infectando canídeos foram identificadas: Hepatozoon canis e Hepatozoon americanum.

As manifestações clínicas da hepatozoonose canina não são claramente definidas. Descrições de infecções por $\boldsymbol{H}$. canis em cães variam de inaparentes a severas (ASSARASAKORN et al., 2006) e a doença geralmente é intercorrente a outras enfermidades imunossupressoras (O'DWYER et al., 2001; BANETH et al., 2003; GAVAZZA et al., 2003) ou outros hemoparasitas (GAVAZZA et al., 2003; AGUIAR et al., 2004; RUBINI et al., 2005), o que dificulta a

\footnotetext{
'Hospital de Clínicas Veterinárias, Universidade Federal do Rio Grande do Sul (UFRGS). Av. Bento Gonçalves, 9090, 91540-000, Porto Alegre, RS, Brasil. E-mail: camila.lasta@ufrgs.br. Autor para correspondência.

IIPrograma de Pós-graduação em Ciências Veterinárias, UFRGS, Porto Alegre, RS, Brasil.

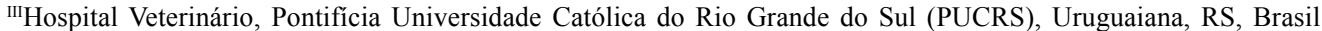

${ }^{\text {IV }}$ Department of Veterinary Pathobiology, Purdue University, West Lafayette, Indiana, U.S.A.

${ }^{\mathrm{V}}$ Faculdade de Veterinária, UFRGS, Porto Alegre, RS, Brasil.
} 
individualização dos seus sinais clínicos (AGUIAR et al., 2004). A infecção por H. americanum geralmente é fatal (PALUDO et al., 2003; RUBINI et al., 2005).

No Brasil, existem poucos relatos de infecção por Hepatozoon spp. em cães, e pouco se sabe a respeito de sua epidemiologia, patogenicidade, seus vetores e sua caracterização genética. Apesar de a doença ter sido descrita nos Estados do Rio de Janeiro (MASSARD, 1979; O’DWYER et al., 2001), São Paulo (O’DWYER et al., 1997), Minas Gerais (MUNDIM et al., 1992), Distrito Federal (PALUDO et al., 2003) e Rio Grande do Sul (SOUZA et al., 2001; MELLO et al., 2006), apenas em 2005 RUBINI et al. identificaram e caracterizaram espécies de Hepatozoon spp. como sendo H. canis, por meio de técnicas moleculares, seguidos por GARCIA DE SÁ et al. (2007) no Rio de Janeiro e RUBINI et al. (2008) em Botucatu, São Paulo.

O presente estudo objetivou relatar um caso de infecção canina por $\boldsymbol{H}$. canis diagnosticado por meio de esfregaço sanguíneo e confirmado pela técnica de PCR associada ao sequenciamento.

\section{MATERIAL E MÉTODOS}

Foi atendido no Hospital de Clínicas Veterinárias da Universidade Federal do Rio Grande do Sul (HCV - UFRGS), Porto Alegre, Rio Grande do Sul (RS), um canino macho, da raça Collie, de quatro anos de idade, apresentando sangramento na ponta das orelhas e emagrecimento progressivo. O proprietário relatou não haver um controle efetivo de carrapatos. Foi coletado sangue com EDTA-K E $_{3}$ sem anticoagulante para realização do hemograma e análises bioquímicas por meio de punção da veia cefálica. Por meio da visualização por microscopia óptica no esfregaço sanguíneo, foram observadas estruturas compatíveis com gamontes de Hepatozoon spp.

DNA foi extraído a partir do sangue total com EDTA-K , $_{3}$ utilizando o kit comercial GFX Genomic Blood DNA Purification Kit, (Amersham Biosciences, UK Limited, Buckinghamshire, England) de acordo com as instruções do fabricante. O DNA extraído foi armazenado a $-20^{\circ} \mathrm{C}$ até o momento das análises moleculares. Para a amplificação do DNA, foram utilizados os iniciadores (primers) para o gene 18S RNA ribossômico sugeridos por INOKUMA et al. (2002): HepF 5' - ATA CAT GAG CAAAAT CTC AAC - 3' e HepR 5' - CTT ATT ATT CCA TGC TGC AG - 3'. A reação em cadeia da polimerase (PCR) foi constituída de tampão $1 \mathrm{X}(\mathrm{pH} 8,5), 2 \mathrm{mM}$ de $\mathrm{MgCl}_{2}$, deoxinucleotídeos (dNTPs) na concentração de $200 \mu \mathrm{M}$, cada primer na concentração de $1 \mu \mathrm{M}, 1,5 \mathrm{U}$ de GoTaq ${ }^{\circledR}$ Flexi DNA Polymerase (Promega, Madison, WI, USA),
$5 \mu \mathrm{L}$ da amostra de DNA e água ultrapura até o volume total de $25 \mu \mathrm{L}$ por reação. A PCR foi realizada utilizando o termociclador Eppendorf Mastercycler gradient thermocycler (Eppendorf Scientific Inc., Westbury, NY, USA) e consistiu de tempo de três minutos de desnaturação inicial a $94^{\circ} \mathrm{C}$, seguido por 35 ciclos de um minuto a $94^{\circ} \mathrm{C}$, dois minutos a $57^{\circ} \mathrm{C}$, dois minutos a $72^{\circ} \mathrm{C}$ e tempo de extensão final de sete minutos a $72^{\circ} \mathrm{C}$. DNA extraído do sangue de três caninos saudáveis provenientes da Universidade de Purdue, nos Estados Unidos (EUA), e água ultrapura foram utilizados como controles negativos. As amostras foram submetidas à eletroforese $(15 \mu \mathrm{L})$ em gel de agarose a $1,5 \%$ por uma hora a $80 \mathrm{~V}$. O gel foi corado com brometo de etídio e fotografado utilizando Epi Chemi II Darkroom (UVP Inc., Upland, CA, USA). Um marcador de peso molecular de 100pb (DNA ladder, Invitrogen, Carlsbad, CA, USA) foi utilizado para comparar o tamanho dos produtos.

O produto da amplificação do tamanho aproximado ao esperado de $625 \mathrm{pb}$ foi purificado a partir do gel de agarose, utilizando-se o kit comercial Zymoclean Gel DNA Recovery Kit (Zymo Research, Orange, CA, USA), de acordo com as instruções do fabricante, e clonados utilizando-se o vetor pGEM-T EasyVector (pGEM-T EasyVector System II, Promega, Madison, WI, USA). Os plasmídios foram purificados utilizando-se o kit comercial QIAprep Spin Miniprep Kit (Qiagen, Valencia, CA, USA). Para evitar possíveis erros cometidos durante a PCR, três amostras provenientes de diferentes colônias foram enviadas para sequenciamento (Purdue Genomics Core Facility at Purdue University, West Lafayette, IN, USA).

As análises moleculares foram realizadas utilizando-se os programas Blastn (BENSON, 1998) e Clustal W2 (THOMPSON et al., 1999). Para a análise filogenética do novo isolado, 19 sequências de $\boldsymbol{H}$. canis e uma sequência de $\boldsymbol{H}$. americanum foram obtidas na base de dados contida no GenBank. Alinhamentos foram realizados utilizando-se o programa Clustal W e ajustadas manualmente. A árvore filogenética foi construída utilizando-se o programa Mega package (TAMURA et al., 2007) pelo método Kimura-neighbourjoining (Figura 1).

\section{RESULTADOS E DISCUSSÃO}

Os sinais clínicos descritos na literatura relacionados com hepatozoonose canina incluem anorexia, emagrecimento, membranas mucosas pálidas, perda de peso, febre, poliúria, polidipsia, dor, vômitos, diarréia, fraqueza, depressão, incoordenação dos membros posteriores, emaciação, linfadenopatia periférica, membranas pálidas e febre (VOYVODA et 


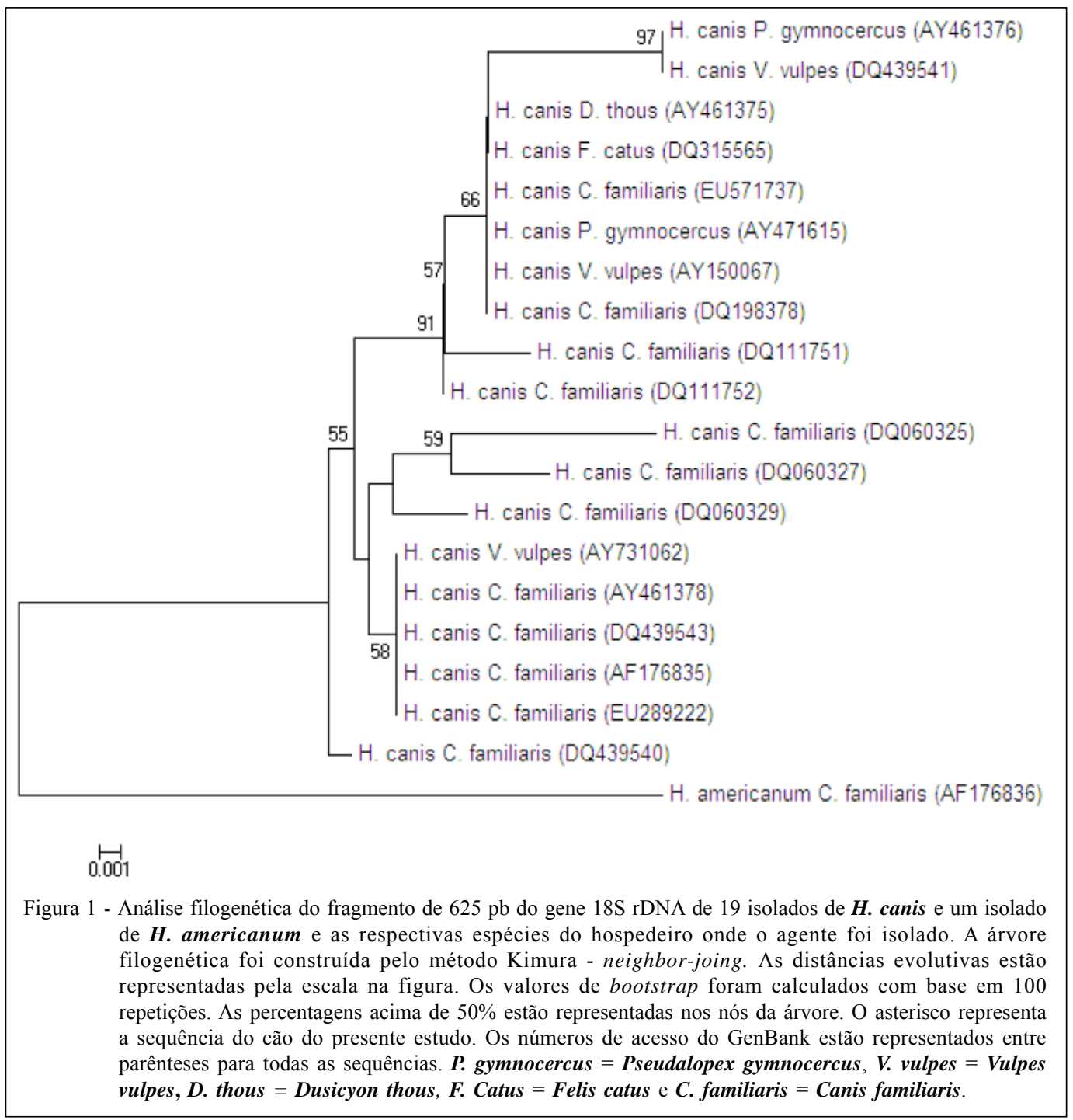

al., 2004). No cão do presente relato, apenas perda de peso foi observada. O paciente apresentava sangramento nas pontas das orelhas, sinal que não está associado a esse patógeno, e sim à infecção por Rangelia vitalli (LORETTI \& BARROS, 2004), o que traz a suspeita de coinfecção, fato não confirmado devido à ausência de método diagnóstico para tal parasita. A coinfecção com outros parasitas transmitidos por carrapatos é comum em cães no Brasil, e agentes como Babesia sp. e Ehrlichia sp. também não podem ser descartados (DANTAS-TORRES, 2008).

A presença de gamontes de Hepatozoon spp. foi observada no esfregaço sanguíneo, sendo essa a forma mais comum do diagnóstico da doença, porém a técnica possui baixa sensibilidade, pois os gamontes podem não ser detectáveis devido ao seu baixo número circulante e a parasitemia intermitente (O'DWYER et al., 2001), além de não distinguir as espécies. As técnicas moleculares, além de servirem como ferramenta de diagnóstico e de estudos epidemiológicos, têm facilitado análises genéticas importantes para a caracterização e distinção das espécies de Hepatozoon spp. (RUBINI et al., 2005)

A confirmação sobre a espécie envolvida na hepatozoonose em diferentes países foi, historicamente, controversa. Com o uso das técnicas moleculares, somente em 2000, BANETH e colaboradores demonstraram uma diferença de 13,59\% de homologia entre o $\boldsymbol{H}$. americanum e $\boldsymbol{H}$. canis na região $18 \mathrm{~S}$ do gene para RNA ribossômico, comprovando definitivamente que as espécies são diferenciadas, causando doenças também distintas.

Apesar de outros autores terem utilizado a mesma técnica de PCR para detecção do Hepatozoon 
spp. com sucesso (RUBINI et al., 2005; GARCIA DE SÁ et al., 2007), bandas inespecíficas e formação de hibridização indesejada pelos primers (primer-dimer) foram observadas, mesmo utilizando diferentes temperaturas de hibridização (Figura 2). A formação de primer-dimer pode ser explicada pelo fato do primer HepR possuir seis pares de base na extremidade 3', que são complementares a ele mesmo. Outra limitação desse protocolo de PCR é que ele não diferencia as espécies de Hepatozoon sp. e deve ser associado a outra técnica molecular como o sequenciamento, o que dificilmente se aplica à rotina laboratorial. Devido aos problemas na técnica de PCR disponível e à ausência de um controle positivo, a estratégia utilizada foi utilizar pelo menos três amostras de DNA de cães saudáveis como controles negativos. Ao comparar-se a amostra do cão infectado com o controle negativo, uma banda extra de tamanho próximo aos 663pb (tamanho esperado para o protocolo utilizado) foi evidenciada no cão em estudo e ausente nos controles negativos. Para

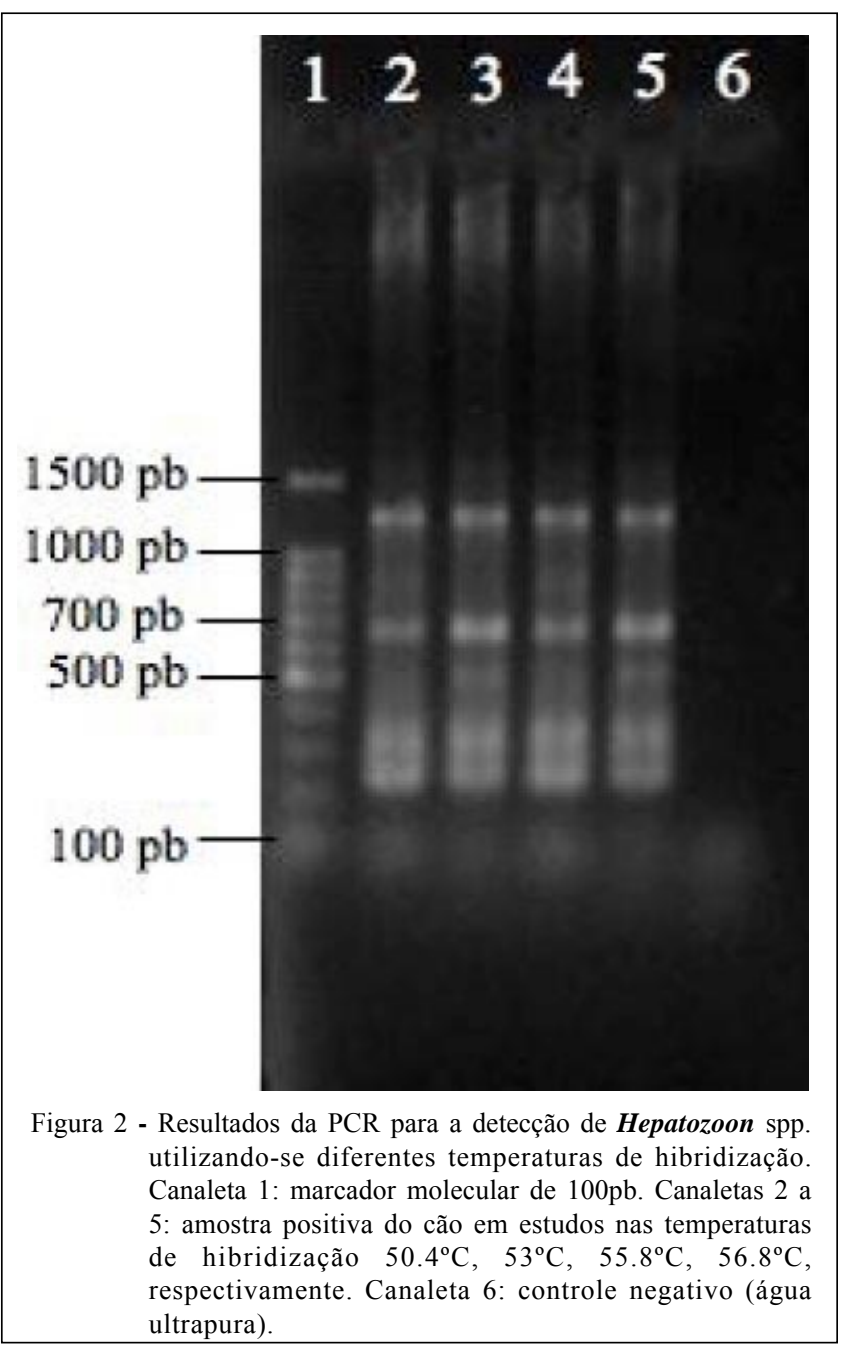

confirmar a identidade do produto, a banda extra foi extraída do gel de agarose e purificada. A purificação da banda a partir do gel evitou que as bandas inespecíficas presentes fossem fatores complicadores para a reação de clonagem e o sequenciamento do fragmento. Quatro reações de sequenciamento foram obtidas com sucesso. Os primers foram excluídos, e a sequência de $625 \mathrm{pb}$ foi submetida à base de dados do GenBank sob o número de acesso \#EU571737 e denominada "isolado de Porto Alegre".

A análise molecular demonstrou que o isolado de Porto Alegre é 100\% homólogo com cinco isolados, dentre eles, três espécies diferentes do cão doméstico: uma raposa proveniente da Espanha (AY150067) e dois canídeos selvagens provenientes do Brasil, sendo um graxaim (Pseudalopex gymnocercus) (AY471615) residente na região dos pampas e um canídeo do gênero Dusicyon thous (AY461375) (CRIADO-FORNELIO et al., 2006), o que sugere que canídeos selvagens podem servir como reservatórios da doença e provavelmente compartilham os mesmos vetores. Outro isolado 100\% homólogo foi o isolado 1 (DQ198378) depositado por RUBINI et al. (2005), que relata o caso de um cão doméstico também proveniente do Brasil. Além disso o isolado de Porto Alegre apresentou homologia de 99\% com um isolado de um gato doméstico proveniente de São Paulo (DQ315565), sugerindo que o H.canis pode infectar outras espécies. Comparando-se com H. americanum, o isolado de Porto Alegre obteve homologia menor que 92\%. CRIADO-FORNELIO et al. (2006) detectaram H. canis em nove de $13(69.2 \%)$ canídeos selvagens provenientes do Rio Grande do Sul. No mesmo trabalho, quando analisados os isolados de cães domésticos e raposas, dois genótipos de $\boldsymbol{H}$. canis foram observados e denominados "Spain1" (AY150067) e "Spain 2" (AY461378). Os autores também observaram uma tendência dos isolados "Spain 1" serem mais comuns nas raposas e Spain 2, nos cães. No entanto, o isolado descrito neste estudo é mais semelhante ao Spain 1 (Figura 1). Esses achados confirmam que a espécie, nesse caso, é o Hepatozoon canis, porém a análise filogenética permanece inconclusiva e precisa de mais investigações.

A técnica pela PCR combinada com sequenciamento confirmou que a hepatozoonose canina, nesse caso, foi causada pelo Hepatozoon canis. A identificação da espécie de Hepatozoon é de extrema importância, 
principalmente após o isolamento de uma espécie de Hepatozoon semelhante ao $\boldsymbol{H}$. americanum em um canídeo selvagem, no Rio Grande do Sul (CRIADOFORNELIO et al., 2006). Devido ao fato de a PCR descrita neste estudo não diferenciar as espécies e ser portanto dependente de posterior sequenciamento, sua utilização na rotina laboratorial é limitada.

\section{CONCLUSÕES}

O presente estudo relata um caso de infecção canina por $\boldsymbol{H}$. canis diagnosticado por meio de esfregaço sanguíneo e confirmado pela técnica de PCR associada ao sequenciamento e alerta para a escassez de dados sobre a ocorrência de hepatozoonose na região Sul do Brasil.

\section{AGRADECIMENTOS}

À Universidade Federal do Rio Grande do Sul e ao Departamento de Patobiologia Comparada da Universidade de Purdue (West Lafayette, Indiana, USA), pelo suporte laboratorial, e à Ana Márcia de Sá Guimarães, pela construção da árvore filogenética.

\section{REFERÊNCIAS}

AGUIAR, D.M. et al. Hepatozoonose canina: achados clínicoepidemiológicos em três casos. Arquivo Brasileiro de Medicina Veterinária e Zootecnia, v.56, n.3, p. 411-413, 2004. Disponível em: <http://www.scielo.br/scielo.php?pid=S0102$09352004000300021 \&$ script $=$ sci arttext $>$. Acesso em: 28 abr. 2007. doi: 10.1590/S0102-09352004000300021.

ASSARASAKORN, S. et al. A retrospective study of clinical hematology and biochemistry of canine hepatozoonosis on hospital populations in Bangkok, Thailand. Comparative Clinical Pathology, v.15, n.2, p.107-109, 2006. Disponível em: < http:/www.springerlink.com/content/ah184124444n4045/. Acesso em: 22 abr. 2007. doi: 10.1007/s00580-006-0606-6.

BANETH, G. et al. Genetic and antigenic evidence supports the separation of Hepatozoon canis and Hepatozoon americanum at the species level. Journal of Clinical Microbiology, v.38, n.3, p.1298-1301, 2000. Disponível em: $<$ http://jcm.asm.org/cgi/content/abstract/38/3/1298>. Acesso em: 02 abr. 2007. doi: 0095-1137/00/\$04.00+0.

BANETH, G; SHKAP, V. Monozoic cysts of Hepatozoon canis. Journal of Parasitology, v.89, n.2, p.379-381, 2003. Disponível em: $<\mathrm{http} / /$ www.journalofparasitology.org/perlserv/?request $=$ get a b s t r a c t \& d o i $=10.1645 \% 2$ F 00202 3395(2003)089[0379\%3AMCOHC]2.0.CO\%3B2>. Acesso em: 02 abr. 2007. doi: 10.1645/0022-3395(2003)089[0379:MCOHC]2.0.CO;2.

BENSON, D.A. et al. GenBank. Nucleic Acids Research, v.26, p.1-7, 1998

CRIADO-FORNELIO, A. et al. New molecular data on mammalian Hepatozoon species (Apicomplexa: Adeleorina) from Brazil and Spain. Journal of Parasitology, v.92, n.1, p.93-99, 2006. Disponível em: <http://cat.inist.fr/ ?aModele $=$ afficheN\&cpsidt $=17646877>$. Acesso em: 15 nov. 2007. doi: 10.1645/GE-464R.1.

DANTAS-TORRES, F. Canine vector-borne diseases in Brazil. Parasites and Vectors, v.1, n.1, 2008. Disponível em: $<$ http:/ / w w w. p u b m e d c e n t r a l. n i h. g o v/ articlerender.fcgi?artid $=2533296 \&$ tool $=$ pmcentrez\&rendertype $=$ abstract $>$. Acesso em: 26 jun. 2008. doi:10.1186/1756-3305-1-25.

GARCIA DE SÁ, A. et al. Detection of Hepatozoon spp in naturally infected brazilian dogs by polymerase chain reaction. International Journal of Applied Research in Veterinary Medicine, v.5, n.2, p.49-51, 2007.

GAVAZZA, A. et al. Observations on dogs found naturally infected with Hepatozoon canis in Italy. Revue de Medicine Veterinarie, v.154, n. 8/9, p.565-571, 2003.

INOKUMA, H. et al. Analysis of the 18S rRNA gene sequence of a Hepatozoon detected in two Japanese dogs. Veterinary Parasitology, v.106, n.3, p.265-271, 2002. Disponível em: $<\mathrm{ht} \mathrm{t}$ p:// w w w s c i e n c e d i e c t . c o m / science? ob=ArticleURL\& udi=B6TD7-45NPFT3$1 \&$ user $=29441 \&$ rdoc $=1 \&$ fmt $=\&$ \& orig $=$ search\&_sort $=\mathrm{d} \& \mathrm{view}=\mathrm{c}$ $\&$ a c c t $=$ C $000003858 \&$ version $=1 \&$ url Ver sion $=0$ \&_userid $=29441 \& \mathrm{md} 5=454 \mathrm{~b} 48 \mathrm{f} 394 \mathrm{ccda} 0 \mathrm{~d} 7 \mathrm{~d} 1 \mathrm{da} 947362629 \mathrm{de}>$. Acesso em: 02 abr. 2007. doi:10.1016/S0304-4017(02)00065-1.

LORETTI, A.P.; BARROS, S.S. Parasitismo por Rangelia vitalli em cães ("nambiuvu", "peste de sangue") - uma revisão crítica sobre o assunto. Arquivos do Instituto Biológico, v.71, n.1, p.101-131, 2004. Disponível em: <http://74.125.93.104/ search?q=cache:jc8soBsxtfYJ:www.biologico.sp.gov.br/docs/arq V 71 1/ 1 oretti.pdf + rang $\%$ C $3 \%$ A 91 i a + vita 1 li\&cd $=10 \& h l=e n \& c t=c \operatorname{lnk} \& g l=u s \& c l i e n t=$ firefox $-a>$. Acesso em: 15 mai. 2007

MASSARD, C.A. Hepatozoon canis (James, 1905) (Adeleida: Hepatozoidae) cães do Brasil, com uma revisão do gênero em membros da ordem carnívora. 1979. 121f. Dissertação (Mestrado em Medicina Veterinária-Parasitologia Veterinária) - Universidade Federal Rural do Rio de Janeiro, Rio de Janeiro, RJ.

MELLO, F.P.S. et al. Hepatozoonose canina - relato de 2 casos. In: CONGRESSO BRASILEIRO DA ANCLIVEPA, 2006, Vitória, ES. Anais... ANCLIVEPA-ES, 2006. V.28, p.64-65.

MUNDIM, A.V. et al. Hepatozoon canis (James, 1905) em cães de Uberlândia, Minas Gerais. Relato de dois casos. Brazilian Journal Veterinary Research Animal Science, v.29 (supl), p.259-261, 1992

O'DWYER, L.H. et al. Ocorrência de infecção múltipla por Babesia canis, Hepatozoon canis e Haemobartonella canis em um cão esplenectomizado. Revista Brasileira de Ciências Veterinárias, v.4, n.2, p.83-84, 1997.

O'DWYER, L.H. et al. Hepatozoon canis infection associated with dog ticks of rural areas of Rio de Janeiro State, Brazil. Veterinary Parasitology, v.94, n.3, p.143-150, 2001. Disponível em: <http://www.ncbi.nlm.nih.gov/pubmed/11113545>. Acesso em: 01 jan. 2007. doi:10.1016/S0304-4017(00)00378-2. 
PALUDO, G.R. et al. Hepatozoon spp.: report of some cases in dogs in Brasília, Brazil. Veterinary Parasitology, v.118, n.34, p.243-248, 2003. Disponível em: http:/www.ncbi.nlm.nih.gov/ pubmed/14729172. Acesso em: 28 abr. 2007. doi:10.1016/ j.vetpar.2003.10.009.

RUBINI, A.S. et al. Molecular identification and characterization of canine Hepatozoon species from Brazil. Parasitology Research, v.97, n.2, p.91-93, 2005. Disponível em: <http:// www.sciencedirect.com/science?_ob=ArticleURL\&_udi=B6TD74J556B2-1\&_user $=29441 \&$ rdoc $=1 \&$ fmt $=$ \&_orig $=$ search $\&_{-}$sort $=\mathrm{d} \&$ vi e w $=\mathrm{c} \&$ _ a c c t $=\overline{\mathrm{C}} 0000003858 \&$ \& e r s i o $n=1 \&$ ur 1 V e r s i o $n=0 \&$ u s e ri d $=2$ $9441 \& \mathrm{md} 5=861 \mathrm{~d} 7 \overline{\mathrm{de}}$ ae $05615 \mathrm{bfaed} 7 \mathrm{f} 6 \mathrm{f} 44 \mathrm{~b} 53 \mathrm{f} 5 \mathrm{e} 2 \mathrm{e}>$. Acesso em: 11 jun. 2007. doi:10.1016/j.vetpar.2005.12.008.

RUBINI, A.S. et al. Molecular and parasitological survey of Hepatozoon canis (Apicomplexa: Hepatozoidae) in dogs from rural area of Sao Paulo state, Brazil. Parasitology Research, v.102, p.895-899, 2008. Disponível em: <http://www.springerlink.com/ content/161r725027282t08/fulltext.html>. Acesso em: 19 jul. 2007. doi:10.1007/s00436-007-0846-7.

SOUZA, C. et al. Relato inédito de Hepatozoon canis no município de Santa Maria no ano de 2001. Ciência Animal, v.10, n.3, p.195-195, 2001.

TAMURA, K. et al. MEGA4: molecular evolutionary genetics analysis (MEGA) software version 4.0. Molecular Biology and Evolution, v.24, p.1596-1599, 2007. Disponível em: $<$ http://mbe.oxfordjournals.org/cgi/content/full/24/8/1596>. Acesso em: 15 dez. 2008. doi:10.1093/molbev/msm092.

THOMPSON, J. D. et al. A comprehensive comparison of multiple sequence alignment programs. Nucleic Acids Research. v.27, n.13, p.2682-9260, 1999.

VOYVODA, H. et al. Clinical Hepatozoon canis infection in a dog in Turkey. Journal of Small Animal Practice, v.45, n.12, p. 613-617, 2004.

Ciência Rural, v.39, n.7, out, 2009. 